\title{
PTSD and Psychosis: A Review
}

\author{
Giovana De Amorim Levin* \\ Department of Psychiatry, Western University, London
}

*Corresponding author: Giovana De Amorim Levin, Department of Psychiatry, Subdivision of Forensic Psychiatry, Western University, London.

\author{
Received Date: April 16, 2019
}

Published Date: May 20, 2019

\section{Introduction}

Post-Traumatic Stress Disorder (PTSD) is arguably the most debilitating psychiatric disorder among anxiety disorders. It was first recognized by the American Psychiatric Association in the DSM-III in 1980 [1]. This diagnosis remained relatively stable in subsequent DSMs. The DSM-IV-TR indicated that the estimated prevalence of PTSD in the adult population in community-based samples in the USA Is approximately 8\%, making it an important public health problem [2]. Although much has been achieved in terms of recognizing the disorder, much advance is needed in terms of optimizing access to health care, fighting stigma, optimizing treatment and improving outcome, including suicide prevention [3-5]. PTSD often presents with multiple and often complex symptomatology, a protracted clinical course, multiple and significant comorbidities and a marked tendency toward chronicity. In the DSM-5, there is recognition that PTSD may also occur as a result of trauma that is not witnessed directly, representing an important step in acknowledging vicarious trauma and its mental health repercussions $[6,7]$. This paper will focus on a special type of presentation seen in a subpopulation of individuals with PTSD, in the form of psychosis. Although not part of the criteria for PTSD, this subpopulation has puzzled clinicians and researchers for decades and it seems to represent a unique part of a spectrum.

\section{Epidemiology}

Trauma-related symptoms have long been recognized in the medical literature under various names (shell shock, combat neurosis) and the initial focus was mainly related to situations of combat and war $[8,9]$. The emphasis broadened in the recent decades and there is a vast literature related to other forms of trauma. Most individuals exposed to a traumatic experience will have some period of adjustment during which some PTSD-like symptoms may manifest themselves. However, the majority will not develop PTSD $[10,11]$. The disorder is estimated to occur in approximately $8 \%$ of the population according to the DSM-IV-TR and the National Comorbidity Study [12]. The subpopulation at risk vary according to their likelihood of exposure to trauma. Higher rates of PTSD are observed in survivors of sexual abuse and assault, victims of violent crime, military combat, captivity, ethnically, politically motivated internment, natural disasters and genocide, among others [13-15]. Lately there has been additional attention to police officers, firefighters and first responders as particularly vulnerable due to their occupation [16-18]. Underlying factors such as family support and pre-existing psychiatric diagnosis may influence the development of PTSD. However, PTSD can also develop in individuals with no pre-existing predisposing conditions, particularly if the exposure to trauma is extreme. Even for those individuals who do not fulfill the criteria for the disorder, some symptoms may still occur and persist and cause impairment in function, representing an important subset of the clinical spectrum. In the DSM-5 (2013), PTSD was included in trauma and stressrelated disorders, separate from anxiety disorders [6]. The DSM-5 criteria for PTSD are included in Appendix I.

\section{Clinical Course}

The effect of trauma in an individual's clinical presentation and ability to function has been widely recognized in special populations such as concentration camp survivors and combatants early in the medical literature. Extensive follow-up studies have shown severe psychiatric sequelae even 50 years later [18]. Early studies of PTSD cases usually excluded patients with psychotic presentations. From a phenomenological standpoint, however, "combat neuroses" (precursor of PTSD) mimicking schizophrenia have for years been described in World War I and II veterans and Vietnam returnees. Before the inclusion of posttraumatic stress disorder (PTSD) into DSM-III in 1980 (American Psychiatric Association, 1980), veterans with the syndrome were not uncommonly diagnosed with schizophrenia and treated with phenothiazines. It is possible that some of these cases in fact were PTSD with psychosis and not a primary psychotic disorder such as schizophrenia [20]. Later, it was recognized that patients with PTSD could present with delusions 
and hallucinations, similar to positive symptoms of schizophrenia $[21,22]$. In the DSM-IV-TR, it was emphasized the broad timing for the initiation of PTSD symptoms after exposure to the traumatic event (from a few months to years). In a significant proportion of cases, the disorder is characterized by a waxing and waning course. Moreover, it is worth noting that symptoms may be "reactivated" after having been dormant for months to years, upon reminders of the trauma and/or newly occurring trauma [23,24]. In addition, comorbid conditions, such as mood disorders and substance abuse, may influence the presentation, course and outcome of PTSD.

\section{Psychosis and PTSD}

Psychosis is currently not part of the criteria for PTSD. However, it presents as a challenge when clinicians try to differentiate these symptoms as part of co-morbidity or as part of a specific clinical subtype of PTSD. Its chronic course, as well as the waxing and waning characteristic of the clinical presentation and at times exacerbation in the context of new trauma poses additional challenge. As previously mentioned, psychotic episodes in the form of positive symptoms have been described in association with PTSD, as well as in the context of psychotic-like dissociative episodes $[25,26]$. This observation was recognized relatively early in the literature, in conjunction with a diagnosis of substance abuse and other co-morbidities such as mood disorders. Other common co-morbidities not commonly associated with psychotic features include generalized anxiety disorder, panic disorder and phobias, somatization disorder and personality disorders [27,28].

In addition to delusions and hallucinations (classically known as positive symptoms of schizophrenia) in association with PTSD, avoidance symptoms, often presenting as withdrawal, may also resemble negative symptoms of schizophrenia. In a populationbased study $(\mathrm{N}=5,877)$, a clear association was found between PTSD and psychotic symptoms [29]. The severity of PTSD in relation to psychosis has been controversial and needs further investigation.

In cases of the presence of co-morbidity, it is important to consider that some of the co-morbidities themselves may be accompanied by psychosis, such as a major depressive episode and substance abuse, and do not necessarily signify that the psychosis is an exclusive part of PTSD $[30,31]$.

Contributing to the complex picture of co-morbidity is the fact that individuals with a primary psychotic disorder are also more likely to have a history of exposure to trauma [32,33]. However, the reliability of these accounts, given that psychosis may contaminate the accounts of events, have come into question. Regardless of the accuracy of the accounts, individuals who experience a psychotic episode may suffer from post-psychosis trauma symptoms, related both to the psychotic experience (most notably paranoid delusions, hallucinations, passivity experiences) and hospitalization [34]. Another scenario would be a co-occurrence of a psychotic disorder, which overshadows the diagnosis of PTSD, which developed secondary to a trauma unrelated to the psychosis itself. It has been suggested that unrecognized PTSD may significantly affect the outcome of patients with psychosis Zimmerman M, et al. [35], as it is the case with various co-morbidities in mental disorder

An important clinical aspect of PTSD is the high rate of suicidal ideation, suicide attempts and completed suicide [36,37]. The cooccurrence with psychosis may compound the problem. These have important implications for clinical practice, emphasizing the importance of screening for the presence of both disorders in this high-risk population.

\section{Conclusion}

The presence of psychosis in the context of PTSD has been described for decades. In the literature, clinicians should be alert to this presentation as one of the following: a) as an integral part of PTSD; b) as a severe form of dissociative phenomena c) as part of a co-morbidity, such as substance abuse and/or a depressive disorder with psychotic features; d) as a primary psychotic disorder such as schizophrenia. In addition, clinicians should consider PTSD as potentially secondary to a psychotic experience, both related to the trauma of the psychosis itself or the process of hospitalization and medical intervention. Further research is needed to elucidate how the association of psychosis with PTSD influences the diagnosis and prognosis, including suicide risk.

\section{Acknowledgement}

None

\section{Conflict of Interest}

No conflict of interest

\section{References}

1. American Psychiatric Association (1980) Diagnostic and statistical manual of mental disorders ( $3^{\text {rd }}$ edn). Washington DC, USA.

2. American Psychiatric Association (2000) Diagnostic and statistical manual of mental disorders ( $4^{\text {th }}$ edn). In, Washington DC, USA, pp 466.

3. Johnson HP, Agius M (2018) A Post-Traumatic Stress Disorder review: the prevalence of underreporting and the role of stigmain the Military. Psychiatr Danub 30(Suppl 7): 508-510.

4. Possemato K, Wray LO, Johnson E, Webster B, Beehler GP (2018) Facilitators and Barriers to Seeking Mental Health Care Among Primary Care Veterans with Posttraumatic Stress Disorder. J Trauma Stress 31(5): 742-752.

5. Rauch SAM, Kim HM, Powell C, Tuerk PW, Simon NM, et al. (2018) Efficacy of Prolonged Exposure Therapy, Sertraline Hydrochloride, and Their Combination Among Combat Veterans with Posttraumatic Stress Disorder: A Randomized Clinical Trial. JAMA Psychiatry: 3412.

6. American Psychiatric Association (2013) Diagnostic and statistical manual of mental disorders ( $5^{\text {th }}$ edn). In: Arlington, VA(Ed), University of Maryland, US.

7. Waegemakres Schiff J, Lane A PTSD Symptoms, Vicarious Traumatization, and Burnout in Front Line Workers in the Homeless Sector. Community Ment Health J 55(3): 454462 .

8. Laufer RS, Brett E, Gallops MS (1985) Symptom patterns associated with posttraumatic stress disorder among Vietnam veterans exposed to war trauma. Am J Psychiatry 142(11): 1304-11.

9. Reid F, Van Everbroeck C (2014) Shell Shock and the Kloppe: war neuroses amongst British and Belgian troops during and after the First World War. Med Confl Surviv 30(4): 252-275 
10. VisserE,GosensT,Den Oudsten BL,DeVriesJ(2017)The course, prediction, and treatment of acute and posttraumatic stress in trauma patients: A systematic review. J Trauma Acute Care Surg 82(6): 1158-1183.

11. Briere J, Dias CP, Semple RJ, Scott C, Bigras N, et al. (2017) Acute Stress Symptoms in Seriously Injured Patients: Precipitating Versus Cumulative Traumaand the Contribution of Peritraumatic Distress. J Trauma Stress 30(4): 381-388.

12. Kessler RC, Sonnega A, Bromet E, Hughes M, Nelson CB (1995) Posttraumatic stress disorder in the National Comorbidity Survey. Arch Gen Psychiatry 52(12): 1048-1060

13. Shalev A, Liberzon I, Marmar C (2017) Post-stress Traumatic Disorder. N Engl J Med 376(25): 2459-2469.

14. Solomon Z, Horesh D, Ein-Dor T, Ohry A (2012) Predictors of PTSD trajectories following captivity: a 35-year longitudinal study. Psychiatry Res 199(3): 188-194

15. Farooqui M, Quadri SA, Suriya SS, Khan MA, Ovais M, et al. (2017) Posttraumatic stress disorder: a serious post-earthquake complication. Trends Psychiatry Psychother 39(2): 135-143.

16. Marchand A, Nadeau C, Beaulieu-Prévost D, Boyer R, Martin M (2015) Predictors of posttraumatic stress disorder among police officers: A prospective study. Psychol Trauma 7(3): 212-221.

17. Boffa JW, Stanley IH, Hom MA, Norr AM, Joiner TE, et al. (2017) PTSD symptoms and suicidal thoughts and behaviors among firefighters. J Psychiatr Res 84: 277-283.

18. Petrie K, Milligan-Saville J, Gayed A, Deady M, Phelps A, et al. (2018) Prevalence of PTSD and common mental disorders amongst ambulance personnel: a systematic review and meta-analysis. Soc Psychiatry Psychiatr Epidemiol 53(9): 897-909.

19. Favaro A, Rodella FC, Colombo G, Santonastaso P (1999) Posttraumatic stress disorder and major depression among Italian Nazi concentration campsurvivors: a controlled study 50 years later. Psychol Med 29(1): 87-95.

20. Hamner MB, Frueh BC, Ulmer HG, Arana GW (1999) Psychotic features and illness severity in combat veterans with chronic posttraumatic stress disorder. Biol Psychiatry 45(7): 846-852.

21. Kastelan A, Francisković T, Moro L, Roncević GI, Grković J, et al. (2007) Psychotic symptoms in combat-related post-traumatic stress disorder. Mil Med 172(3): 273-277.

22. Alsawy S, Wood L, Taylor PJ, Morrison AP (2015) Psychotic experiences and PTSD: exploring associations in a population survey. Psychol Med. 45(13): 2849-2859.

23. Utzon-Frank N, Breinegaard N, Bertelsen M, Borritz M, Eller NH, et al. (2014) Occurrence of delayed-onset post-traumatic stress disorder: a systematic review and meta-analysis of prospective studies. Scand J Work Environ Health 40(3): 215-229.

24. HoreshD, Solomon Z, Keinan G, Ein-Dor T (2013) The clinical picture of late-onset PTSD: a 20-year longitudinal study of Israeli war veterans. Psychiatry Res 208(3): 265-273.

25. Pinto PA, Gregory RJ (1995) Posttraumatic stress disorder with psychotic features. Am J Psychiatry 152(3): 471-472.

26. Sautter FJ, Brailey K, Uddo MM, Hamilton MF, Beard MG, et al. (1999) PTSD and comorbid psychotic disorder: Comparison with veterans diagnosed with PTSD or psychotic disorder. J Trauma Stress 12(1): 7388.

27. Deering CG, Glover SG, Ready D, Eddleman HC, Alarcon RD (1996) Unique patterns of comorbidity in post-traumatic stress disorder from different sources of trauma. Compr Psychiatry 37(5): 336-346.

28. Hamner MB (1997) Psychotic features and combat-associated PTSD. Depress Anxiety 5(1): 34-38.

29. Sareen J, Cox BJ, Goodwin RD, J G Asmundson G (2005) Co-occurrence of posttraumatic stress disorder with positive psychotic symptoms in a nationally representative sample. J Trauma Stress 18(4): 313-322.

30. Zweben JE, Clark HW, Smith DE (1994) Traumatic experiences and substance abuse: mapping the territory. J Psychoactive Drugs 26(4): 327-344.

31. Sautter FJ, Brailey K, Uddo MM, Hamilton MF, Beard MG, et al. (1999) PTSD and comorbid psychotic disorder: Comparison with veterans diagnosed with PTSD or psychotic disorder. J Trauma Stress 12(1): 7378.

32. Mueser K, Goodman LB, Trumbetta S, Rosenberg S, Osher C, et al. (1998) Trauma and posttraumatic stress disorder in severe mental illness. J Consult Clin Psychol 66: 493-499.

33. Goodman LA, Thompson KM, Weinfurt K, Corl S, Acker P, et al. (1999) Reliability of reports of violent victimization and posttraumatic stress disorder among men and women with serious mental illness. J Trauma 12(4): 587-599.

34. Berry K, Ford S, Jellicoe-Jones L, Haddock G (2013) PTSD symptoms associated with the experiences of psychosis and hospitalisation. Clin Psychol Rev 33(4): 526-538.

35. Zimmerman M, Mattia JI (1999) Psychotic subtyping of major depressive disorder and posttraumatic stress disorder. J Clin Psychiatry 60(5): 311400 .

36. Lutwak N, Dill C (2017) PTSD and Risk of Suicide. Mil Med 182(9): 1684.

37. Pompili M, Sher L, Serafini G, Forte A, Innamorati M, et al. (2013) Posttraumatic stress disorder and suicide risk among veterans. J Nerv Ment Dis 201(9): 802-812. 